\title{
The prevalence of non-alcoholic fatty liver disease in healthy young persons
}

\author{
Gokcan Okur, ${ }^{1}$ Zehra Karacaer $^{2}$ \\ ${ }^{1}$ Department of Radiology, Etimesgut Military Hospital, Ankara, Turkey \\ ${ }^{2}$ Department of Infectious Diseases and Clinical Microbiology, Etimesgut Military Hospital, Ankara, Turkey
}

\begin{abstract}
OBJECTIVE: This aim of the present study was to determine prevalence of non-alcoholic fatty liver disease (NAFLD) in healthy young persons admitted for annual medical check-ups.

METHODS: A retrospective study was conducted in a military hospital. Total of 254 healthy males were included and participants were divided into 2 groups according to presence and grade of NAFLD. Demographic data, biochemical test results, and ultrasonography findings were collected from all patients. Statistical analyses were performed using SPSS software, version 22.0 (SPSS, Inc., Chicago, IL, USA).

RESULTS: Prevalence of NAFLD was $10.6 \%$. Significant differences were found with regard to age; levels aspartate transaminase, alanine transaminase, gamma-glutamyl transferase, and alkaline phosphatase; body mass in$\operatorname{dex}(B M I) ;$ and presence of NAFLD ( $p=0.014, p=0.022, p=0.003, p \leq 0.001, p=0.004$, and $p \leq 0.001$, respectively). When compared to those with grade 1 NAFLD, levels of alanine transaminase, fasting blood glucose, gammaglutamyl transferase, triglycerides, total cholesterol and age variables were higher in those with grade 2 NAFLD. However, no statistically significant difference was noted when comparing grades of NAFLD.

CONCLUSION: Though this study included patients with normal BMI and normal laboratory test results, presence of NAFLD was not rare in these otherwise healthy young men. Liver enzyme levels were within normal limits; however, there was slight tendency to be high consistent with presence and grade of NAFLD.
\end{abstract}

Keywords: Healthy; non-alcoholic fatty liver disease; prevalence; ultrasonography.

Tonalcoholic fatty liver disease (NAFLD) is a clinicopathological entity leading to major health issues, like metabolic syndrome (MS), in both adults and children. It is described as a lipid accumulation in excess of $5 \%$ of the liver wet weight, without alcohol consumption $[1,2,3]$. A group of pathologies ranging from simple hepatic steatosis to non-alcoholic steatohepatitis (NASH) and cirrhosis are defined as NAFLD. The word "hepatic steatosis" in this context specifies simple benign fatty infiltration of the liver. However, NASH refers to inflammation and necrosis of the hepatocytes, ac-

Received: October 11, 2016 Accepted: October 22, 2016

Correspondence: Dr. Zehra KARACAER. Gulhane Egitim ve Arastirma Hastanesi, Enfeksiyon Hastaliklari ve Klinik Mikrobiyoloji, 06010 Ankara, Turkey.

Tel: +90 312 - 2491011 e-mail: zehrakaracaer@yahoo.com

(c) Copyright 2016 by Istanbul Northern Anatolian Association of Public Hospitals - Available online at www.kuzeyklinikleri.com 
companied by steatosis, and is diagnosed with a tissue biopsy [3].

The frequency of NAFLD varies throughout the different regions of the world, and is markedly predominant in certain places. In the United States (US), its frequency is estimated to be from $16 \%$ to $23 \%$, and in Europe and the Middle East it ranges from $20 \%$ to $30 \%[3,4]$. In Turkey, the prevalence of NAFLD varies from $19.8 \%$ to $42 \%$ in adults, and from $6 \%$ to $11.8 \%$ among children $[1,2,5,6]$. However, in those patients with MS, its prevalence is markedly higher, increasing to $69.94 \%$ [7].

To the best of our knowledge, there have been few studies published on the prevalence of NAFLD in healthy subjects in Turkey [8]. Moreover, the prevalence values from the US and Europe could be associated with a spectrum of different diseases, and cannot be applied directly to a healthy population. Therefore, this study was aimed at establishing the prevalence of NAFLD in individuals with no apparent risk factors for this disease in Turkey.

\section{MATERIALS AND METHODS}

For this research, a retrospective study was conducted in the radiology department in a military hospital in Turkey between 01 January 2012 and 31 October 2014. In total, 254 patients were included in this study population, which was taken from individuals admitted to the hospital for annual medical check-ups. These subject had normal parameters for their fasting blood glucose (FBG), aspartate transaminase (AST), alanine transaminase (ALT), $\gamma$-glutamyl transferase (GGT), alkaline phosphatase (ALP), triglycerides (TG), total cholesterol (TC), body mass index (BMI) and arterial blood pressure.

NAFLD was determined and graded according to the ultrasonography (USG) findings. Due to the absence of grade 3 NAFLD, all of the subjects were divided into two groups according to the presence and grade of NAFLD.

Our study group was similar in terms of age (20-45 years old), and all of them were males. The exclusion criteria were positive serology for hepa-
TABLE 1. Demographic data and biochemical results of subjects

\begin{tabular}{lcc} 
Variables & Median & Min.-Max. \\
\hline Age $($ year $)$ & 27 & $21-41$ \\
BMI $\left(\mathrm{kg} / \mathrm{m}^{2}\right)$ & 24 & $19-25$ \\
Weight $(\mathrm{kg})$ & 74 & $56-90$ \\
Height $(\mathrm{cm})$ & 178 & $166-193$ \\
ALT $(0-45 \mathrm{U} / \mathrm{L}) *$ & 19 & $7-45$ \\
AST $(0-35 \mathrm{U} / \mathrm{L})^{*}$ & 21 & $10-34$ \\
FBG $(74-106 \mathrm{mg} / \mathrm{dl})^{*}$ & 92.0 & $73-105$ \\
GGT $(0-55 \mathrm{U} / \mathrm{L})^{*}$ & 17 & $6-51$ \\
ALP $(38-155 \mathrm{U} / \mathrm{L}) *$ & 64 & $15-116$ \\
TG $(50-200 \mathrm{mg} / \mathrm{dl})^{*}$ & 84.5 & $50-200$ \\
TC $(110-200 \mathrm{mg} / \mathrm{dl})^{*}$ & 167 & $103-200$ \\
\hline
\end{tabular}

ALP: Alkaline phosphatases; ALT: Alanine aminotransferase; AST: Aspartate aminotransferase; BMI: Body mass index; FBG: Fasting blood glucose; GGT: $y$-glutamyltransferase; Min: Minimum; Max: maximum; TC: Total cholesterol; TG: Triglycerides; *: Normal value.

titis $B$ virus and hepatitis $C$ virus, the presence of other causes of liver disease, regular or excessive alcohol consumption ( $>40 \mathrm{gr} /$ day), medical history which is significant for hepatic steatosis, established MS and obesity.

The medical record data for all of the subjects was collected through a retrospective review of their charts, including: age, BMI, AST, ALT, FBG, TC, TG, ALT, AST, GGT, ALP and USG results.

A hepatic USG examination was performed by two experienced radiologists with a GE Logiq 5 PRO ultrasound system (GE Medical Systems, Milwaukee, WI, USA) using a convex broadband (4-10 Mhz) transducer. In the assessment, NAFLD was defined as diffusely increased liver echogenicity when compared to the right kidney cortex, and graded according to the following criteria [9].

Grade 1: Increased diffuse echogenicity, but normal vascular walls and diaphragm echogenicity.

Grade 2: The intrahepatic vein/artery walls and diaphragm echogenicity were partly obscured by the increased parenchyma echogenicity in a diffuse manner.

Grade 3: The diaphragm wall echogenicity was 
TABLE2. Results of the presence and the grade of NAFLD in patients

\begin{tabular}{|c|c|c|c|c|c|c|c|}
\hline & \multicolumn{2}{|c|}{$\begin{array}{l}\text { The presence of NAFLD } \\
\text { (Median/Min.-Max.) }\end{array}$} & \multirow[t]{2}{*}{$\mathrm{p}$ value ${ }^{\mathrm{b}}$} & \multicolumn{3}{|c|}{$\begin{array}{l}\text { The grade of NAFLD } \\
\text { (Median/Min.-Max.) }\end{array}$} & \multirow[t]{2}{*}{$p$ value } \\
\hline & $\begin{array}{l}\text { Present } \\
(\mathrm{n}=27)\end{array}$ & $\begin{array}{l}\text { Absent } \\
(n=227)\end{array}$ & & $\begin{array}{l}\text { Grade } 1 \\
(n=20)\end{array}$ & $\begin{array}{l}\text { Grade } 2 \\
(n=7)\end{array}$ & $\begin{array}{l}\text { Grade } 3 \\
(n=0)\end{array}$ & \\
\hline Age (year) & $31(22-41)$ & $27(20-40)$ & $0.014^{c}$ & $30.5(22-41)$ & $31(23-40)$ & - & 0.978 \\
\hline BMI $\left(\mathrm{kg} / \mathrm{m}^{2}\right)$ & $25(21-25)$ & $23(19-25)$ & $<0.001^{c}$ & $25(21-25)$ & $25(22-25)$ & - & 0.974 \\
\hline Weight (kg) & $79(65-90)$ & $74(56-90)$ & $0.012^{c}$ & $79.5(69-90)$ & $78(65-88)$ & - & 0.781 \\
\hline Height (cm) & $178(167-188)$ & $178(166-193)$ & 0.814 & $179.5(167-188)$ & $176(172-186)$ & - & 0.657 \\
\hline $\operatorname{ALT}(0-45 \mathrm{U} / \mathrm{L})^{\mathrm{a}}$ & $23(15-41)$ & $21(10-34)$ & $0.003^{c}$ & $22.5(15-41)$ & $25(15-35)$ & - & 0.579 \\
\hline AST $(0-35 \mathrm{U} / \mathrm{L})^{\mathrm{a}}$ & $23(16-34)$ & $19(7-45)$ & $0.022^{c}$ & $23(16-34)$ & $21(17-34)$ & - & 0.435 \\
\hline FBG $(74-106 \mathrm{mg} / \mathrm{dl})^{\mathrm{a}}$ & $93(80-103)$ & $91(73-105)$ & 0.201 & $92(80-101)$ & $97(86-103)$ & - & 0.33 \\
\hline GGT $(0-55 \mathrm{U} / \mathrm{L})^{\mathrm{a}}$ & $25(11-49)$ & $17(6-51)$ & $<0.001^{c}$ & $24.5(11-49)$ & $26(19-33)$ & - & 0.58 \\
\hline ALP $(38-155 \mathrm{U} / \mathrm{L})^{\mathrm{a}}$ & 79 (18-99) & $63(15-116)$ & $0.004^{c}$ & 79 (18-99) & $73(59-93)$ & - & 0.719 \\
\hline $\mathrm{TG}(50-200 \mathrm{mg} / \mathrm{dl})^{\mathrm{a}}$ & $87(56-199)$ & $84(50-200)$ & 0.385 & $80.5(58-183)$ & $128(56-199)$ & - & 0.15 \\
\hline TC $(110-200 \mathrm{mg} / \mathrm{dl})^{\mathrm{a}}$ & 169 (133-199) & $167(103-200)$ & 0.323 & 168 (133-199) & $170(147-193)$ & - & 472 \\
\hline
\end{tabular}

ALP: Alkaline phosphatases; ALT: Alanine aminotransferase; AST: Aspartate aminotransferase; BMI: Body mass index; FBG: Fasting blood glucose; GGT: Y-glutamyltransferase; Min: Minimum; Max: maximum; TC: Total cholesterol; TG: Triglycerides; NAFLD: Non-alcoholic fatty liver disease; a: Normal values; b: Mann-Whitney U; c: a p-value of $<0.05$ was considered statistically significant.

not visualized, and the posterior segments of the liver were poorly assessed.

The Declaration of Helsinki and Good Clinical Practice Guidelines were respected during the entire process of enrolling patients and collecting, analysing and reporting the data. Verbal consent was obtained from patients. Approval from the local ethics committee was obtained before conducting this study (8000-1-15/ 16 February 2015).

The statistical analysis was performed using the IBM SPSS 22.0 software. As described above, all of the subjects were divided into two groups, and descriptive statistics were applied to each group. The normal distribution of the variables was evaluated using the Kolmogorov-Smirnov test, and non-parametric methods were used for the non-normally distributed values (Mann-Whitney $U$ and Kruskal Wallis). Because of the non-normal distribution, the continuous variables were obtained as the median (minimum-maximum). The categorical variables were presented as the frequency and percentage, and a $\mathrm{p}$-value of $<0.05$ was considered to be statistically significant.

\section{RESULTS}

A total of 254 male participants were included in this study. The demographic data and biochemical test results are shown in Table 1, and all of the patients had normal arterial blood pressure. The USG examination revealed NAFLD in a total of 27 of the subjects; of these, 20 had grade 1 and seven had grade 2. There were no instances of grade 3 NAFLD found in our subjects. According to our results, the prevalence of NAFLD was $10.6 \%$.

Although the levels of the liver enzymes were within the normal limits, there was a slight increasing tendency, according to the grade of NAFLD, in some of the applied tests. For example, the ALT, FBG, GGT, TG and TC values and the age were found to be higher in those subjects with grade 2 NAFLD than in those with grade 1 NAFLD. However, no difference was noted between the grade and the variables (Table 2).

Significant differences were found between the age, weight, AST, ALT, GGT, ALP and BMI and the presence of NAFLD $(p=0.014, p=0.012, p=0.022$, 
$\mathrm{p}=0.003, \mathrm{p} \leq 0.001, \mathrm{p}=0.004$ and $\mathrm{p} \leq 0.001$, respectively) (Table 2).

\section{DISCUSSION}

The detailed biological behaviour of NAFLD is unclear, but it seems to be determined by the severity of the histological damage. Cross-sectional studies for NAFLD have shown that most subjects exhibit fatty liver only, and it is widely believed that the progression to steatohepatitis or fibrosis over time is a rare condition. Some publications have reported the frequency of advanced hepatic fibrosis to be $30 \%-40 \%$ at the time of diagnosis, whereas wellestablished cirrhosis was found in $10 \%-15 \%$ of the patients. A progression to hepatocellular carcinoma has also been emphasized in literature [10]. Although no significant increase has been reported in the mortality rates specifically related to NAFLD, those patients with NASH usually reveal higher mortality rates $(35 \%-85 \%)$ when compared to the overall population [4].

There are various clinical conditions that may accompany NAFLD; for example, MS is a very important etiological factor in the development of NAFLD. It is defined by the following conditions: high waist circumference, hyperlipidaemia, hypertension and a high FPG level. Those patients having MS features are at a high risk for NAFLD. Other conditions presumed to be associated with NAFLD include ethnicity, certain medications (e.g. tamoxifen, corticosteroids and oestrogens), excess carbohydrates, rapid weight loss, altered small bowel anatomy, certain metabolic diseases (e.g. hypobetalipoproteinaemia, abetalipoproteinaemia, Wilson's disease, etc.), infections (e.g. chronic hepatitis C virus, human immunodeficiency virus and acquired immune deficiency syndrome) and some evolving pathologies (e.g. polycystic ovary syndrome, hypothyroidism, etc.) [11].

Similar to other clinical conditions, with the increase in the prevalence of obesity, NAFLD has increased over time. Because it is the most common aetiology of cryptogenic cirrhosis (cirrhosis that cannot be explained by other causes), NAFLD has become a serious medical problem in the US [3].
The prevalence of obesity is $32 \%$ for adults and $17 \%$ for adolescents in the US population [12], and the prevalence of NAFLD has been reported to be $75 \%$ in morbidly obese patients, with cirrhosis detected in $3-11 \%$ of them [4]. In pertinent publications, the prevalence of NAFLD in Turkey are $11.8 \%$ among obese children [2] and 32\% among obese adults [5].

In our research, we found the prevalence of NAFLD to be $10.6 \%$; however, we cannot establish a comparison due to the absence of related publications on healthy young subjects. We thought that the annual check-up provides the awareness of NAFLD. Therefore, our patients might take precautions against occurrence or progression of NAFLD.

It is known that the frequency of NAFLD frequency increases with age $[5,13]$. Our results showed lower prevalence rates when compared with the US and European statistics for adults [4], but similar rates to those children with NAFLD in Turkey $[1,2,5,6]$. Unfortunately, our results cannot be compared with similar age groups in Turkey.

The prevalence of NAFLD was found to be $23.2 \%$ in a transient elastography study on the basis of a controlled attenuation parameter (CAP) [8]. It is known that CAP obtained by transient elastography is a more sensitive method compared to US due to its capability to detect less severe grades of hepatic steatosis $[14,15]$. Kaya et al. [8]. may observed higher prevalence because of using more sensitive method.

The more well-known risk factors for NAFLD are a high BMI, advanced age and the presence of MS $[5,10,16]$. Our study group was composed of subjects that tested negative for hepatitis, with no identified risk factors for NAFLD, but there was a significant difference with regard to the age, weight, BMI, ALT, AST, GGT and ALP in terms of the development of NAFLD, which was observed in one of ten subjects. In spite of the participants' normal hepatic enzyme levels, there was a slight tendency toward increasing, compatible with the grading of the NAFLD, in some of the applied tests.

Although there could be one possible mechanism for the development of NAFLD in our subjects, due to the retrospective study design composed of 
healthy young subjects, we cannot establish a hypothesis for this. However, we can estimate that an increase in the grade of NAFLD may cause a slight tendency toward an increase in the hepatic enzymes. Therefore, we suggest some preventive changes be considered at this stage, such as lifestyle modifications, dietary changes and/or sporting activities, before progression to grade 3 NAFLD.

Our results showed that an apparent clinico-laboratory deterioration cannot be determined by routine physical or laboratory tests. We suggest that a liver USG is a very cost-effective and easily available imaging method which can help in the detection of these subjects before the development of severe fatty infiltration in the future. Furthermore, a strong correlation between NAFLD and coronary artery disease may be crucial to determining those subjects who have relevant risk factors for cardiovascular disease $[16,17,18]$. Therefore, USG can be applied as a screening tool along with routine check-ups.

Many studies have revealed that liver enzymes can be helpful in the determination or prediction of NAFLD and its grading, but due to the high variability of liver enzymes (including AST and ALT), we cannot conclude that these enzymes play a definite role in the accurate diagnosis of NAFLD [17]. In their study, Abangah et al. [19] found that the $\mathrm{BMI}$ and $\mathrm{TG}$ are the most effective factors in determining the severity of fatty liver disease and USG grading of patients with NAFLD. However, AST was not found to be a reliable marker, according to that study, because it may show alterations in many conditions [19]. Some authors have suggested that the parameters related to MS (such as the BMI, ALT, AST, GGT and FBG) are significantly different in NAFLD, when compared to non-NAFLD cases. In addition, the BMI and AST were found to be statistically different [7].

Bellentani et al. [20] showed that $79 \%$ and 55\% of patients with NAFLD had normal ALT levels. Therefore, ALT has no impact on the entire histological spectrum of NAFLD, and normal levels may accompany underlying NASH. This suggests an independent variable, and that the histological spectrum cannot be significantly different between elevated and normal ALT values [21]. Obika et al.
[22] also showed that liver enzyme changes might not have any associations with NAFLD Moreover, approximately half of the NAFLD patients having persistently normal ALT values revealed potentially progressive liver disease [23]; therefore, the ALT level is not a reliable indicator in determining liver damage severity [24].

The prevalence of NAFLD has been rated and graded according to the USG results in many publications $[9,11,13,25,26]$. Overall, hepatic USG is a simple, noninvasive technique that is widely used in clinical practice to detect the fatty infiltration of the liver [27]. The sensitivity and specificity of USG for detecting NAFLD have been reported to range from $64 \%$ to $94 \%$ and from $84 \%$ to $97.3 \%$, respectively $[9,28,29,30]$.

This study did have some limitations. For instance, our study group was composed of males only, because the participant recruitment was restricted to patients in a military hospital. Consequently, we could not evaluate our results with regard to gender differentiation. Another limitation was that liver biopsies were not performed in our subjects because there were no definite risk factors for advanced NAFLD in this population. Therefore, we were not able to predict any subjects with NASH among these participants.

In most cases, NAFLD has a benign course, and due to the hazards associated with biopsies and the lack of established effective therapies, the role and effectiveness of liver biopsies remains a controversial issue. However, a liver biopsy is an accurate method for the diagnosis of NASH, and can detect the severity of liver damage in a long-term survey. The risk factors for advanced disease include an age $>45$ years old, the presence of type 2 diabetes mellitus or morbid obesity $\left(B M I>39 \mathrm{~kg} / \mathrm{m}^{2}\right)$ and an AST/ALT ratio $>1[3,10]$. It seems more reasonable to avoid unnecessary biopsy interventions, limiting those to patients who are likely to have more advanced liver disease.

Clinical and laboratory tests may not be a sensitive methods for diagnosing NAFLD at an early stage, and a complete history and physical examination should be used simultaneously with laboratory 
test results and USG findings [19]. We suggest that an annual check-up should be done with USG in NAFLD screening since, as in our study, mild or moderate NAFLD can often be detected in subjects with no risk factors. Those individuals at a mild or moderate stage should be informed and followed to prevent the progression of the disease.

In conclusion, despite the fact that our study group was composed of healthy subjects with normal BMIs and normal laboratory test results, the prevalence of NAFLD was not a rare occurrence. Therefore, the metabolic determinants that show lipid accumulation in the liver may not play major predictive roles in patients with NAFLD. We thought that our results can be adapted for every male subject of similar age who have annual checkup and no regular or excessive alcohol consumption in our country. Further studies are required for a detailed evaluation of these individuals.

\section{Conflict of Interest: None declared.}

Financial Disclosure: The authors declared that this study has received no financial support.

Authorship contributions: Concept - G.O., Z.K.; Design - G.O., Z.K.; Supervision - G.O., Z.K.; Data collection \&/or processing - G.O., Z.K.; Analysis and/or interpretation - Z.K.; Literature search - Z.K.; Writing - G.O., Z.K.; Critical review - G.O., Z.K.

\section{REFERENCES}

1. Yüksel F, Türkkan D, Yüksel I, Kara S, Celik N, Samdancı E. Fatty liver disease in an autopsy series of children and adolescents. Hippokratia 2012;16:61-5.

2. Arslan N, Büyükgebiz B, Oztürk Y, Cakmakçi H. Fatty liver in obese children: prevalence and correlation with anthropometric measurements and hyperlipidemia. Turk J Pediatr 2005;47:23-7.

3. Bayard M, Holt J, Boroughs E. Nonalcoholic fatty liver disease. American Family Physician 2006;73:11.

4. Kara M, Erdal M. A public health issue that increased prevalence: Non-alcoholic fatty liver disease. TAF Prev Med Bull 2014;13:65-76.

5. Celebi S, Ataseven H, Mengucuk E, Deveci SH, Acık Y, Bahcecioglu İH. Epidemic features of nonalcoholic fatty liver in urban community of Elazıg. Akademik Gastroenteroloji Dergisi 2006;5:41-6.

6. Uyanikoglu A, Coskun M, Binici DN, Ozturk Y. The frequency of hepatosteatosis in inactive hepatitis b carries. Viral Hepatitis Journal 2011;17:62-5.
7. Demir ME, Aydogan T, Pamukcu M, Ulas T, Eren MA. Ultrasound evaluation of metabolic syndrome patients with hepatosteatosis. Journal of clinical and Experimental Investigations 2013;4:153-8. Crossref

8. Kaya E, Demir D, Alahdab YO, Yilmaz Y. Prevalence of hepatic steatosis in apparently healthy medical students: a transient elastography study on the basis of a controlled attenuation parameter. Eur J Gastroenterol Hepatol 2016;28:1264-7. Crossref

9. Incedayı M, Pekkafali MZ, Sildiroglu HO, Basekim CC, Kizilkaya E. Sonographic and histopathological correlation in diffused fatty liver. Anatol J Clin Investig 2012;6:1-5.

10. Sass DA, Chang P, Chopra KB. Nonalcoholic fatty liver disease: a clinical review. Digestive Diseases and Sciences January 2005.

11. Puri P, Sanyal AJ. Nonalcoholic fatty liver disease: definitions, risk factors, and workup, (review). Clinical Liver Disease 2012;1:4. Crossref

12. Ogden CL, Carroll MD, Curtin LR, McDowell MA, Tabak CJ, Flegal KM. Prevalence of overweight and obesity in the United States, 1999-2004. JAMA 2006;295:1549-55. Crossref

13. Wang CC, Hsu CS, Liu CJ, Kao JH, Chen DS. Association of chronic hepatitis $\mathrm{B}$ virus infection with insulin resistance and hepatic steatosis. J Gastroenterol Hepatol 2008;23:779-82. Crossref

14. Sasso M, Beaugrand M, de Ledinghen V, Douvin C, Marcellin P, Poupon R, et al. Controlled attenuation parameter (CAP): a novel $\mathrm{VCTE}^{\mathrm{TM}}$ guided ultrasonic attenuation measurement for the evaluation of hepatic steatosis: preliminary study and validation in a cohort of patients with chronic liver disease from various causes. Ultrasound Med Biol 2010;36:1825-35. Crossref

15. Schwenzer NF, Springer F, Schraml C, Stefan N, Machann J, Schick F. Non-invasive assessment and quantification of liver steatosis by ultrasound, computed tomography and magnetic resonance. J Hepatol 2009;51:433-45. Crossref

16. Sarikaya S, Vurdem UE, Erdem FH, Inci F, Erdem A. Relationship between the extent of coronary artery disease and fatty liver severity in nonalcoholic fatty liver disease patient. AIBU Izzet Baysal Tip Fakultesi Dergisi 2012:7:1-3.

17. Agarwal AK, Jain V, Singla S, Baruah BP, Arya V, Yadav R, Singh VP. Prevalence of non-alcoholic fatty liver disease and its correlation with coronary risk factors in patients with type 2 diabetes. J Assoc Physicians India 2011;59:351-4.

18. Mohammadi A, Bazazi A, Maleki-Miyandoab T, GhasemiRad M. Evaluation of relationship between grading of fatty liver and severity of atherosclerotic finding. Int J Clin Exp Med 2012;5:251-6.

19. Abangah G, Yousefi A, Asadollahi R, Veisani Y, Rahimifar P, Alizadeh S. Correlation of Body Mass Index and Serum Parameters With Ultrasonographic Grade of Fatty Change in Non-alcoholic Fatty Liver Disease. Iran Red Crescent Med J 2014;16:12669. Crossref

20. Bellentani S, Scaglioni F, Marino M, Bedogni G. Epidemiology of non-alcoholic fatty liver disease. Dig Dis 2010;28:155-61.

21. Mofrad P, Contos MJ, Haque M, Sargeant C, Fisher RA, Luketic VA, et al. Clinical and histologic spectrum of nonalcoholic fatty 
liver disease associated with normal ALT values. Hepatology 2003;37:1286-92. Crossref

22. Obika M, Noguchi H. Diagnosis and evaluation of nonalcoholic fatty liver disease. Exp Diabetes Res 2012. Crossref

23. Fracanzani AL, Valenti L, Bugianesi E, Andreoletti M, Colli A, Vanni E, et al. Risk of severe liver disease in nonalcoholic fatty liver disease with normal aminotransferase levels: a role for insulin resistance and diabetes. Hepatology 2008;48:792-8. Crossref

24. Khosravi S, Alavian SM, Zare A, Daryani NE, Fereshtehnejad SM, Daryani NE, et al. Non-alcoholic fatty liver disease and correlation of serum alanin aminotransferase level with histopathologic findings. Hepat Mon 2011;11:452-8.

25. Korkmaz P, Aykın N, Cevik FC, Alpay Y, Naz H, Gulduren HM. Hepatic Steatosis in Inactive Hepatitis B Carriers: Prevalence, Evaluation of Viral and Biochemical Parameters. Viral Hepatitis Journal 2013;19.
26. Inci A, Meral CE. Ultrasonographic assessment of the prevalence of hepatic steatosis in inactive hepatitis B carriers. Viral Hepatitis Journal 2013;19:46-8. Crossref

27. Foster KJ, Dewbury KC, Griffith AH, Wright R. The accuracy of ultrasound in the detection of fatty infiltration of the liver. $\mathrm{Br}$ J Radiol 1980;53:440-2. Crossref

28. Joseph AE, Saverymuttu SH, al-Sam S, Cook MG, Maxwell JD. Comparison of liver histology with ultrasonography in assessing diffuse parenchymal liver disease. Clin Radiol 1991;43:26-31.

29. Saverymuttu SH, Joseph AE, Maxwell JD. Ultrasound scanning in the detection of hepatic fibrosis and steatosis. Br Med J (Clin Res Ed) 1986;292:13-5. Crossref

30. Palmentieri B, de Sio I, La Mura V, Masarone M, Vecchione R, Bruno $S$, et al. The role of bright liver echo pattern on ultrasound B-mode examination in the diagnosis of liver steatosis. Dig Liver Dis 2006;38:485-9. Crossref 